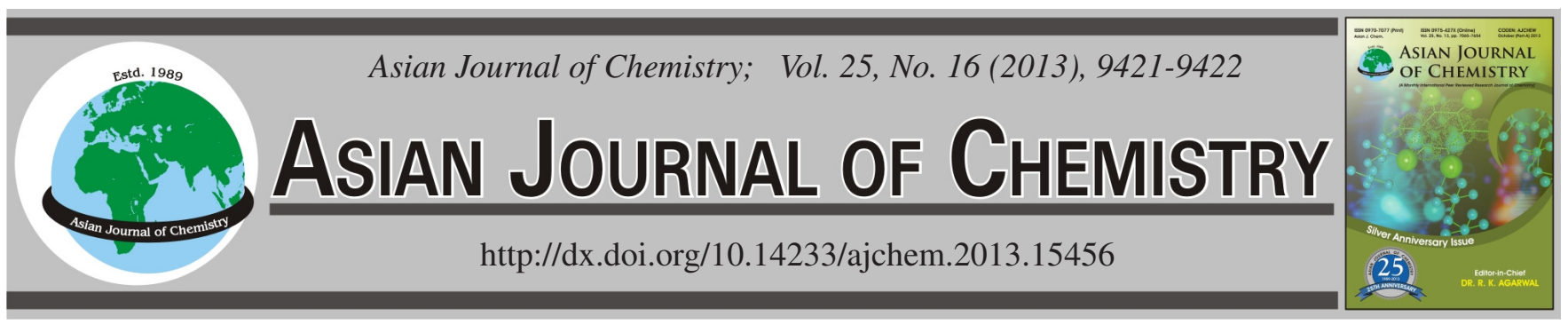

NOTE

\title{
Measurement of Total Sugar Content of Residue from Bioenergy Pig Excreta in Marsh-Gas Sinks
}

\author{
G. PENG ${ }^{1, *}$, E.V. DAVIS ${ }^{2}$, L.X. WANG ${ }^{1}$ and C.W. ZHANG ${ }^{3}$
}

${ }^{1}$ School of Chemical Engineering, Ningbo University of Technology, Ningbo 315016, P.R. China

${ }^{2}$ Department of Chemistry, Clemson University, Clemson 29631, USA

${ }^{3}$ Department of Biochemistry, Jiaxing University, Xiaxing 314001, P.R. China

*Corresponding author: E-mail: gepengv@ hotmail.com

(Received: 9 March 2013;

Accepted: 27 September 2013)

AJC-14196

Marsh gas from pig excreta is considering as a new bioenergy. 30 marsh-gas sinks of pig excreta are used as samples in Nanhu area of |
Jiaxing in China. The material and the last residue are different between solution and insoluble substances. The study concerns to measure
the total sugar content of residue from bioenergy pig excreta by 3,5-dinitrosalicylic acid. The main consequence shows that the residue
contained sugar amount is $107.3 \mathrm{~g} / \mathrm{L}$. The method is helpful to improve the utilization efficiency of marsh-gas and extend a new way of
circular economy and agricultural development.
Key Words: Pig excreta, Bioenergy, Marsh gas, Total sugar content, 3,5-Dinitrosalicylic acid.

As oil and coal resources are over exploited on the world scale, people start to focus on the energy exhausting and decreasing of environmental pollutions ${ }^{1}$. With these influences, the applications of methane techniques and saving precious energy are being promoted ${ }^{2-4}$. The methane techniques on pig fertilizer have been extended for more than 20 years in Nanhu area of Jiaxing city in China. At present, the serious problem is that the factor of produced gas and energy is not sufficiently enough to generate electricity. Among bio-energy plants, it mainly bases on the carbohydrate and glycolysis of flammable gas to get energy by burning ${ }^{5-6}$.

The sugar from plant is just called carbohydrate. There are large amount of rough fiber, which are regarded as the main energy of marsh-gas sink to convert into gas. As the substance acted upon by the ferment, the remained substances in the marsh-gas sink become very sticky, smell and insoluble with fiber material, which can extremely easily cause thick rural land and waterpollution. These problems come from a lot of economical and human factors. Therefore, the study of the total sugar content of residue from bioenergypig excretais based on plant of energy-sugar, which is the main energy ingredient, is carried on project determination, assessing methane conversion, looking for local glycolysis methane gas production and the current capacity to solve the problem for providing scientific basis in future ${ }^{7,8}$.
The carbohydrates of methane remain, such as amylon, cellulose, etc., which can reduce sugar by hydrolysis. The reducing sugar is mainly consisting of single sugar such as glucose and amylomaltose. Their existence can partly explain the process of operation condition of glycolysis in the marshgas pond. So the total sugar of the remains can be determined by 3,5-dinitrosalicylic acid ${ }^{9,10}$.

Selection of marsh-gas sinks of pig excreta: Thirty marsh-gas sinks of pig excreta are used as samples in Nanhu area of Jiaxing in China. The materials and the last residue are different between solution and insoluble substances. Thus, the proportion is not consistent. One litre samples are taken in order to compare with each other.

Thermostatic water tank Guohua SHA-C; Centrifuge Eppendorf 5702; Electric balance Minqiao FA1104N; Spectrophotometer Shimadzu UV-1550.

\section{Reagent:}

(1) $1 \mathrm{mg} / \mathrm{mL}$ dextrose as the standard solution: After drying to constant weight of the AR glucose $100 \mathrm{mg}$, to put them into a small beaker, adding a small amount of distilled water to be dissolved, transfering to a $100 \mathrm{~mL}$ flask, constanting volume with distilled water to $100 \mathrm{~mL}$, mixing, reserving them in the refrigerator at $4{ }^{\circ} \mathrm{C}$.

(2) 3,5-Dinitrosalicylic acid reagent: Added $6.3 \mathrm{~g}$ of 3,5dinitrosalicylic acid and $262 \mathrm{~mL}$ of $2 \mathrm{M} \mathrm{NaOH}$ into $500 \mathrm{~mL}$ 
TABLE-1

TOTAL SUGAR CONTENTS OF RESIDUE FROM PIG EXCRETA IN 30 MARSH-GAS SINKS

\begin{tabular}{|c|c|c|c|c|c|}
\hline Sample & Total sugar $(\mathrm{g} / \mathrm{L})$ & Sample & Total sugar $(\mathrm{g} / \mathrm{L})$ & Sample & Total sugar $(\mathrm{g} / \mathrm{L})$ \\
\hline 1 & 110 & 11 & 109.2 & 21 & 120.4 \\
\hline 2 & 111.3 & 12 & 101.7 & 22 & 104.5 \\
\hline 3 & 100.9 & 13 & 89.5 & 23 & 100.9 \\
\hline 4 & 98.8 & 14 & 109.2 & 24 & 88.6 \\
\hline 5 & 87.3 & 15 & 100.2 & 25 & 132.4 \\
\hline 6 & 121.3 & 16 & 90.7 & 26 & 123 \\
\hline 7 & 110.8 & 17 & 89.4 & 27 & 126 \\
\hline 9 & 132.3 & 19 & 112.3 & 29 & 99.3 \\
\hline 10 & 101.2 & 20 & 112.4 & 30 & 100.9 \\
\hline
\end{tabular}

The statistics analysis was executed by SPSS13.0 software, the average value is $107.26, \mathrm{SD}=2.488531, \mathrm{n}=30$. The date was remarked with Mean $\pm \mathrm{SD}$. There is statistical significance by using $\mathrm{t}$ examination and analysis of variance to mean comparison $(\mathrm{P}<0.05)$.

hydrothermal solution with Seignette salt, then adding $5 \mathrm{~g}$ crystal phenol and $5 \mathrm{~g}$ sodium sulfite, stirring until being dissolved totally. Finally, adding the distilled water to constant volume of $1000 \mathrm{~mL}$, keeping it in a brown bottle.

(3) Iodine-potassium iodide solution: Weighed $5 \mathrm{~g}$ iodine and $10 \mathrm{~g}$ potassium iodide, then dissolved in $100 \mathrm{~mL}$ distilled water.

(4) Phenolphthalein indicator: Weighed $0.1 \mathrm{~g}$ phenolphthalein, then dissolved in $250 \mathrm{~mL} 70 \%$ ethanol.

(5) $6 \mathrm{M} \mathrm{HCl}$ and $6 \mathrm{M} \mathrm{NaOH}$ of $100 \mathrm{~mL}$.

Statistics method: The statistics analysis was executed by SPSS13.0 software, the date was remarked with Average Value $\pm \mathrm{SD}$, using $\mathrm{t}$ examination and analysis of variance among the serious.

To accurately weigh $5 \mathrm{~mL}$ of soluble substances from pig excreta, add them into the $200 \mathrm{~mL}$ beaker. Firstly, a small amount of distilled water was taken to make it mushy. Secondly, $100 \mathrm{~mL}$ distilled water was added to be homogenized. Finally, to put it in the $50{ }^{\circ} \mathrm{C}$ thermostatic water bath to heat for 20 min to leach reduce sugar. The leached solution (including sediment) was transferred into the two $50 \mathrm{~mL}$ centrifuge tubes, to centrifuge at $4000 \mathrm{rpm}$ for $5 \mathrm{~min}$ and wash the precipitate by $40 \mathrm{~mL}$ distilled water, to centrifuge again. The supernatants were collected in the $100 \mathrm{~mL}$ flask, to take the constant volume of distilled water to mix homogenizedly. To be regarded it as the measured solution.

To accurately weigh $5 \mathrm{~g}$ of indissoluble rough fiber and so on from pig excreta, take it into the $100 \mathrm{~mL}$ flask, add $15 \mathrm{~mL}$ distilled water and $10 \mathrm{~mL} 6 \mathrm{M} \mathrm{HCl}$ added. Hydrolysis was done with heating in boiling water for $0.5 \mathrm{~h}$ by use of iodine-potassium iodide solution to check. Cooling after hydrolysis, to add a drop of phenolphthalein indicator, the solution was neutralized to reddish colour with $6 \mathrm{M} \mathrm{NaOH}$. To put it into the constant volume $100 \mathrm{~mL}$ with distilled water and uniformly mix them and then filtrate. Take $10 \mathrm{~mL}$ supernatent and transfer it to another $100 \mathrm{~mL}$ flask, homogenizedly mix again. Finally, we considered it as the solution to measure total sugar. Table-1 shows the results of measurement.

\section{Conclusion}

Thirty samples of pig excreta from Nanhu area of Jiaxing in China were determined. Their total sugar contents were executed and calculated by the statistical analysis soft 3,5dinitrosalicylic acid. The sugar amount of the residue is 107.3 $\pm 2.488531 \mathrm{~g} / \mathrm{L}$, there is a statistically significant different by using t examination and analysis of variance to average value of comparison $(\mathrm{P}<0.05)$. It explained that methane glycolysis was incomplete, produced gas was described and the conditions need to be improved by glycolysis to produce more gas as possible and increase the conversion rate. The experiment can be used as a valuable method to biogas glycolysis. It is also helpful to improve the gas utilization efficiency and expand new ways for agriculture and recycling economy.

\section{REFERENCES}

1. J. Krautrkamer, Economics of Natural Resource Scarcity; The State of the Debate, Resources for the Future, Washington D.C., pp. 05-14 (2005).

2. L. Stroem, A. Lamppa and T.R. Christensen, Wetlands Ecol. Manage., 15, 43 (2007).

3. J.L.M. Bubier and T.R. Moore, Trends Ecol. Evol., 9, 460 (1994).

4. T.R. Christensen, N. Panikov, M. Mastepanov, M. Mastepanov, A. Joabsson, A. Stewart, M. Öquist, M. Sommerkorn, S. Reynaud and B. Svensson, Biogeochemistry, 64, 337 (2003).

5. C. Jury, E. Benetto, D. Koster, B. Schmitt and J. Welfring, Biomass Bioener, 34, 54 (2010).

6. B. Wahlund, J.Y. Yan and M. Westermark, Biomass Bioener, 23, 27 (2002).

7. R. Wooley, M. Ruth, D. Gassner and J. Sheehan, Biotechnol. Prog., 15, 794 (1999).

8. C.L. Tian, B. Guo and C.C. Liu, Chin. J. Bioprocess Eng., 1, 14, (2005).

9. L.X. Zhang, T.F. Zhang and L.Y. Li, Biochemical Experimental Methods and Techniques, Higher Education Press, Beijing, edn. 2, pp. 47-80 (1992).

10. Y.L. Han and X.Y. Luo, Chin. J. Food Hygiene, 7, 47 (1995). 